\title{
Article \\ Co-Zn-MOFs Derived N-Doped Carbon Nanotubes with Crystalline Co Nanoparticles Embedded as Effective Oxygen Electrocatalysts
}

\author{
Wendi Zhang, Xiaoming Liu, Man Gao, Hong Shang and Xuanhe Liu *
}

Citation: Zhang, W.; Liu, X.; Gao, M.; Shang, H.; Liu, X. Co-Zn-MOFs Derived N-Doped Carbon Nanotubes with Crystalline Co Nanoparticles Embedded as Effective Oxygen Electrocatalysts. Nanomaterials 2021 11, 261. https://doi.org/10.3390/ nano11020261

Received: 10 December 2020

Accepted: 18 January 2021

Published: 20 January 2021

Publisher's Note: MDPI stays neutral with regard to jurisdictional claims in published maps and institutional affiliations.

Copyright: (c) 2021 by the authors. Licensee MDPI, Basel, Switzerland. This article is an open access article distributed under the terms and conditions of the Creative Commons Attribution (CC BY) license (https:// creativecommons.org/licenses/by/ $4.0 /)$.
School of Science, China University of Geosciences (Beijing), Beijing 100083, China; zhangwd@cugb.edu.cn (W.Z.); liuxm@cugb.edu.cn (X.L.); goyeman@outlook.com (M.G.); shanghong@cugb.edu.cn (H.S.)

* Correspondence: liuxh@cugb.edu.cn; Tel.: +86-010-82322758

\begin{abstract}
The oxygen reduction reaction (ORR) is a crucial step in fuel cells and metal-air batteries. It is necessary to expand the range of efficient non-precious ORR electrocatalysts on account of the low abundance and high cost of $\mathrm{Pt} / \mathrm{C}$ catalysts. Herein, we synthesized crystalline cobalt-embedded $\mathrm{N}$ doped carbon nanotubes (Co@CNTs-T) via facile carbonization of $\mathrm{Co} / \mathrm{Zn}$ metal-organic frameworks (MOFs) with dicyandiamide at different temperatures $\left(t=600,700,800,900{ }^{\circ} \mathrm{C}\right)$. Co@CNTs- 800 possessed excellent ORR activities in alkaline electrolytes with a half wave potential of $0.846 \mathrm{~V}$ vs. RHE (Reversible Hydrogen Electrode), which was comparable to Pt/C. This three-dimensional network, formed by Co@CNTs-T, facilitated electron migration and ion diffusion during the ORR process. The carbon shell surrounding the Co nanoparticles resulted in Co@CNTs-800 being stable as an electrocatalyst. This work provides a new strategy to design efficient and low-cost oxygen catalysts.
\end{abstract}

Keywords: metal-organic frameworks; N-doped carbon; oxygen reduction reaction

\section{Introduction}

Excessive consumption of fossil fuels gives rise to an energy dilemma as well as environmental concerns. Therefore, it is necessary to expand new energy storage technologies, such as electrochemical energy storage [1,2]. Metal-air batteries and fuel cells are promising for energy conversion and storage devices [3,4]. Nevertheless, the sluggish kinetics of cathodic oxygen reduction reactions (ORR) needs to be urgently addressed [5]. Pt-based catalysts are effective as catalysts in ORR [6,7]. However, their high cost and scarcity make the development of other types of ORR electrocatalysts with low price and high activity extremely important, such as metal-free [8,9] and transition metal electrocatalysts [10,11].

Metal-free electrocatalysts like carbon-based catalysts have been widely studied for their good stability. However, the average electrocatalytic performance has limited their applications [12,13]. The $3 \mathrm{~d}$ transition metal electrocatalysts (such as $\mathrm{Ni}, \mathrm{Fe}$, and Co) are considered to have promising catalytic activity due to their unique electronic structure $[14,15]$. Co-based catalysts are attractive due to the higher stability on account of their immunity to the Fenton reaction [16,17]. Heteroatom doping (such as N, S, P) [18,19], introduction of defects [20,21], and morphological control [22] were considered as effective methods to improve the electrocatalytic performance. Metal-organic frameworks (MOFs) are of considerable interest in terms of alternative active metal centers, regulable structures, and high specific surface area $[23,24]$. MOFs are considered to be eminent precursors in obtaining porous nanocomposites having a variety of morphology features and chemical components by adjusting the precursors and calcination conditions [25,26].

$\mathrm{Zn} / \mathrm{Co}$-based MOFs are promising precursors to fabricate heteroatom-doped metalsupported carbon materials but more defects were expected to be created by Zn volatilization at high temperature. However, $\mathrm{Zn}$ volatilizing at high temperature could prevent the accumulation of other metal ions [27-29]. The morphology and structure of the catalysts 
also play a significant role in enhancing their electrocatalytic activity. Herein, we fabricated a three-dimensional network composed of $\mathrm{N}$-doped carbon nanotubes with crystalline Co nanoparticles, embedded, by calcination of $\mathrm{Co} / \mathrm{Zn} \mathrm{MOF}$ and dicyandiamide (DCD) as the precursor. The three-dimensional network, termed Co@CNTs, was constructed by regulating the annealing temperature and the mass ratios of $\mathrm{Co} / \mathrm{Zn} \mathrm{MOF}$ and $\mathrm{DCD}$. The obtained Co@CNTs composite showed a nanotube structure, while crystalline Co nanoparticles were embedded at the end of the CNTs, surrounded by the carbon shell. The Co@CNTs prepared at $800^{\circ} \mathrm{C}(\mathrm{Co} / \mathrm{Zn}$ MOF:DCD = 1:1) exhibited more densely packed and uniform nanotubes and better ORR performance. The half-wave potential was $0.846 \mathrm{~V}$ vs. RHE and showed good electrochemical stability, comparable to commercial $\mathrm{Pt} / \mathrm{C}$. This work could provide a synthetic method for economical and durable electrocatalysts with three-dimensional networks for ORR.

\section{Materials and Methods}

\subsection{Preparation of $\mathrm{Co}-\mathrm{Zn}-\mathrm{BDC}$}

All chemical reagents were bought from Aladdin Reagent (Aladdin, Shanghai, China) and used directly in the present experiments. The Co-Zn-BDC was constructed by ultrasound [30]. First, $0.75 \mathrm{mmol}$ 1,4-benzenedicarboxylic acid $\left(\mathrm{H}_{2} \mathrm{BDC}\right)$ was dissolved to $36 \mathrm{~mL}$ mixed solution of DMF, ethanol, and deionized water with a volume ratio of 16:1:1. Subsequently, $0.75 \mathrm{mmol} \mathrm{CoCl} \cdot 6 \mathrm{H}_{2} \mathrm{O}$ and $0.75 \mathrm{mmol} \mathrm{ZnCl}$ were added, respectively. After the $\mathrm{Co}^{2+}$ and $\mathrm{Zn}^{2+}$ salts were fully dissolved, $0.8 \mathrm{~mL}$ of triethylamine (TEA) was then added to the solution. After stirring for $5 \mathrm{~min}$ the above mixture underwent $8 \mathrm{~h}$ ultrasonication $(40 \mathrm{kHz})$. The resulting pink precipitate was collected by centrifugation and rinsed with ethanol and water, respectively, followed by vacuum freeze-drying. Co-BDC was prepared by the same method without the introduction of $\mathrm{Zn}$ ions.

\subsection{Preparation of Co@CNTs-T and Control Samples}

The mixture of Co-Zn-BDC and DCD with mass ration of 1:1 underwent calcination at high temperatures $\left(600,700,800\right.$ and $\left.900{ }^{\circ} \mathrm{C}\right)$ for $2 \mathrm{~h}$ under nitrogen protection at a heating rate of $5{ }^{\circ} \mathrm{C} \mathrm{min}^{-1}$. The products were labelled as Co@CNTs-600, Co@CNTs-700, Co@CNTs-800, and Co@CNTs-900, respectively. The schematic synthetic process is depicted in Scheme 1. Co-MOF-800 was prepared by annealing Co-BDC at the temperature of $80{ }^{\circ} \mathrm{C}$, and $\mathrm{Co}-\mathrm{Zn}-\mathrm{MOF}-800$ was synthesized by annealing CO-Zn-BDC at the temperature of $800{ }^{\circ} \mathrm{C}$.

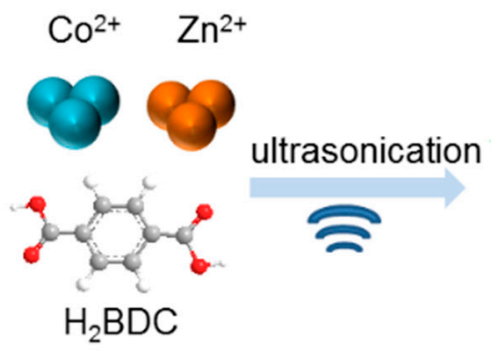

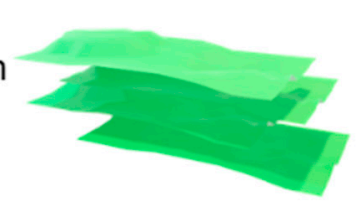

Co-Zn-BDC

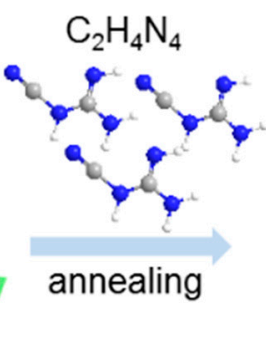

Scheme 1. Schematic diagram for the synthetic route of Co@CNTs.

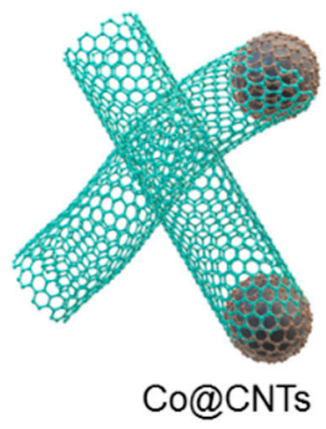

\subsection{Sample Characterization Methods}

Scanning electron microscopy (SEM, ZEISS MERLIN Compact, $20 \mathrm{Kv}$, Jena, Germany) and field emission transmission electron microscope (TEM, FEI G2 F30 200 kV, Hillsboro, OR, USA) were carried out to observe the micro-morphology of Co@CNTs-T. Power X-ray diffraction (XRD, D8 SmartLab (Karlsruhe, Germany) with $\mathrm{Cu} \mathrm{K} \alpha$ radiation $(\lambda=0.15418 \mathrm{~nm}))$ patterns were characterized to obtain crystal structures. X-ray photoelectron spectroscopy (XPS, Escalab 250Xi, Waltham, America) was used to probe the chemical 
states of surface elements. Fourier transform infrared spectroscopy (FTIR IRTracer-100, Tokyo, Japan) was employed to analyze chemical and structural information. Thermogravimetric analysis (TGA, NETZSCH-200F3, Selbu, Germany) was used to analyse thermal stability. ICP-MS Agilent 7700 (Palo Alto, CA, USA) analyzed the composition of metal elements. Raman (Renishaw, London, UK) was used to analyse the purity of materials. BET (ASAP 2020, Norcross, GA, USA) analysed the specific surface area and pore size. The Organic Element Analyzer (EA Vario EL cube, Bonn, Germany) was used to analyse the CHN of materials.

\subsection{Electrochemical Measurement}

Typically, a homogeneous black solution was formed by fully dispersing a $3 \mathrm{mg}$ sample of Co@CNTs-T, $7 \mathrm{mg}$ carbon black, and $1.25 \mathrm{~mL}$ ethanol under ultrasound for $3 \mathrm{~h}$. Then $36 \mu \mathrm{L}$ of the ink and $6 \mu \mathrm{L}$ Nafion solution $(0.5 \mathrm{wt} \%)$ were coated on the prepolished rotating ring-disk electrode (RRDE, $4 \mathrm{~mm}$ in diameter) followed by drying at room temperature. A homogeneous $\mathrm{Pt} / \mathrm{C}$ ink solution was formed by fully dispersing $3 \mathrm{mg}$ commercial $\mathrm{Pt} / \mathrm{C}$ and $1.25 \mathrm{~mL}$ ethanol under ultrasound for $3 \mathrm{~h}$. Then $36 \mu \mathrm{L}$ of the ink and $6 \mu \mathrm{L}$ Nafion solution $(0.5 \mathrm{wt} \%)$ were coated on the pre-polished RRDE electrode followed by drying at room temperature. The RRDE electrode covered with catalyst was used as the working electrode and the saturated $\mathrm{Ag} / \mathrm{AgCl}$ electrode was used as the reference electrode. The graphite electrode was used as the counter electrode and the electrolyte was $0.1 \mathrm{M} \mathrm{KOH}$ solution $\left(\mathrm{N}_{2}\right.$ or $\mathrm{O}_{2}$ were pumped into $0.1 \mathrm{M} \mathrm{KOH}$ solution for half an hour respectively). Cyclic voltammetry was used at the scan rate $50 \mathrm{mV} \mathrm{s}^{-1}$ and linear sweep voltammetry at the scan rate of $5 \mathrm{mV} \mathrm{s}^{-1}$ with a rotating speed of $1600 \mathrm{rpm}$. Besides chronoamperometry at $0.7 \mathrm{~V}$ (vs. RHE) testing of the prepared sample was conducted in the RRDE test system.

\section{Results}

\subsection{Structural Properties of the Co@CNTs-T}

Scanning electron microscope (SEM) was used to investigate the morphology of Co$\mathrm{Zn}-\mathrm{BDC}$, and the SEM image shown in Figure S1a displays nanosheet morphology of Co-Zn-BDC. The XRD pattern of Co-Zn-BDC is shown in Figure S1b, the peaks appearing at $8.8^{\circ}, 15.8^{\circ}, 17.8^{\circ}, 28.8^{\circ}, 30.8^{\circ}$ demonstrated its crystal structure, which was consistent with previous reports [31,32]. Fourier transform infrared spectroscopy (FTIR) was carried out to determine the chemical and structural information. The FTIR data of Co-Zn-BDC is shown in Figure S1c. The strong absorption peaks of $\mathrm{H}_{2} \mathrm{BDC}$ (black) appearing at 1673 and $1424 \mathrm{~cm}^{-1}$ originate from the asymmetric and symmetric stretching vibrations of crude carboxylate groups (-COOH). For Co-Zn-BDC (red), the peaks were red shifted to 1573 and $1362 \mathrm{~cm}^{-1}$, attributed to the coordination of carboxylate organic ligands and metal centers [33]. Then, inductively coupled plasma-mass spectrometry (ICP-MS) was used to determine the $\mathrm{Co} / \mathrm{Zn}$ content of $\mathrm{Co}-\mathrm{Zn}-\mathrm{BDC}$; the result indicated that Co-Zn-BDC contained $76.73 \mathrm{wt} \% \mathrm{Co}$ and $23.27 \mathrm{wt} \% \mathrm{Zn}$, respectively. Besides, thermogravimetric analysis was performed to analyze the thermal stability of Co-Zn-BDC. As shown in Figure S1d, Co-Zn-BDC remained stable with a slight decrease in weight before $400^{\circ} \mathrm{C}$. As the temperature rose, the weight was lost obviously due to pyrolysis.

The morphology of all Co@CNTs-T was also studied by SEM. The SEM images are shown in Figure $1 \mathrm{a}-\mathrm{d}$. Particles with a few nanotubes are seen from the SEM image of Co@CNTs-600 in Figure 1a. With the temperature rising in the range of $600-800{ }^{\circ} \mathrm{C}$, more nanotubes arose and were distributed evenly. They were connected to constitute a three-dimensional network structure, which was beneficial to electron transfer in the electrocatalytic process [34]. Nevertheless, when the annealing temperature reached $900{ }^{\circ} \mathrm{C}$, there were no visible nanotubes and only large-sized nanoparticles with diameter of 50-200 nm could be seen. We concluded that higher annealing temperatures were not suitable to form nanotubes. Besides, the mass ratio of Co-Zn-BDC/DCD was of crucial importance in producing uniform nanotubes. The SEM images for Co@CNTs-800 by 
annealing Co-Zn-BDC/DCD with different mass ratios (2:1 and 1:2) are shown in Figure S2. It can be seen that no visible nanotubes were produced. The mass ratio of 1:1 was most suitable for the formation of a three-dimensional network structure.
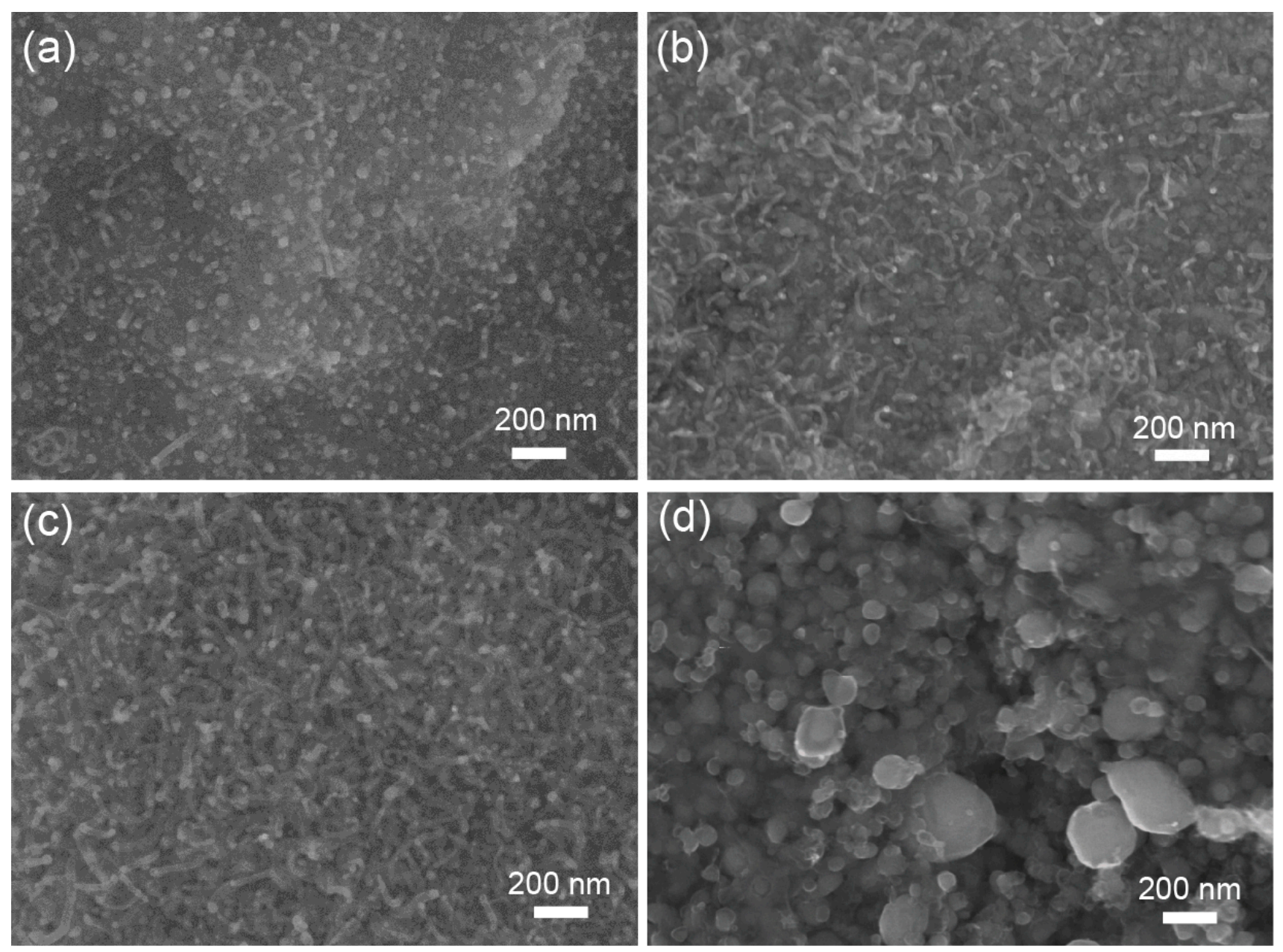

Figure 1. SEM images of (a) Co@CNTs-600, (b) Co@CNTs-700, (c) Co@CNTs-800, and (d) Co@CNTs-900.

Transmission electron microscopy (TEM) was used to further study the morphology and phase composition of Co@CNTs-800. The TEM image in Figure 2a revealed that the prepared nanotubes were of hundreds of nanometers in length with diameter of $\sim 50 \mathrm{~nm}$, the nanoparticles were formed at the end of the nanotubes and the diameters of the nanoparticles were about 20-60 nm. The high-resolution TEM image (Figure 2b) displayed nanoparticles with spacing of $0.20 \mathrm{~nm}$, which were indexed as the Miller indices (112) of Co. The results revealed that the crystalline Co nanoparticles were embedded in nanotubes, the nanoparticles were surrounded with a carbon layer, and the lattice fringe spacing of the carbon layer was $0.31 \mathrm{~nm}$, assigned to the (002) plane of graphitic carbon [35]. The elemental mapping images in Figure $2 \mathrm{c}-\mathrm{f}$ indicated that $\mathrm{C}, \mathrm{Co}$, and $\mathrm{N}$ elements were distributed evenly in the nanotubes. It was noted that more Co elements were concentrated in the nanoparticles region. 

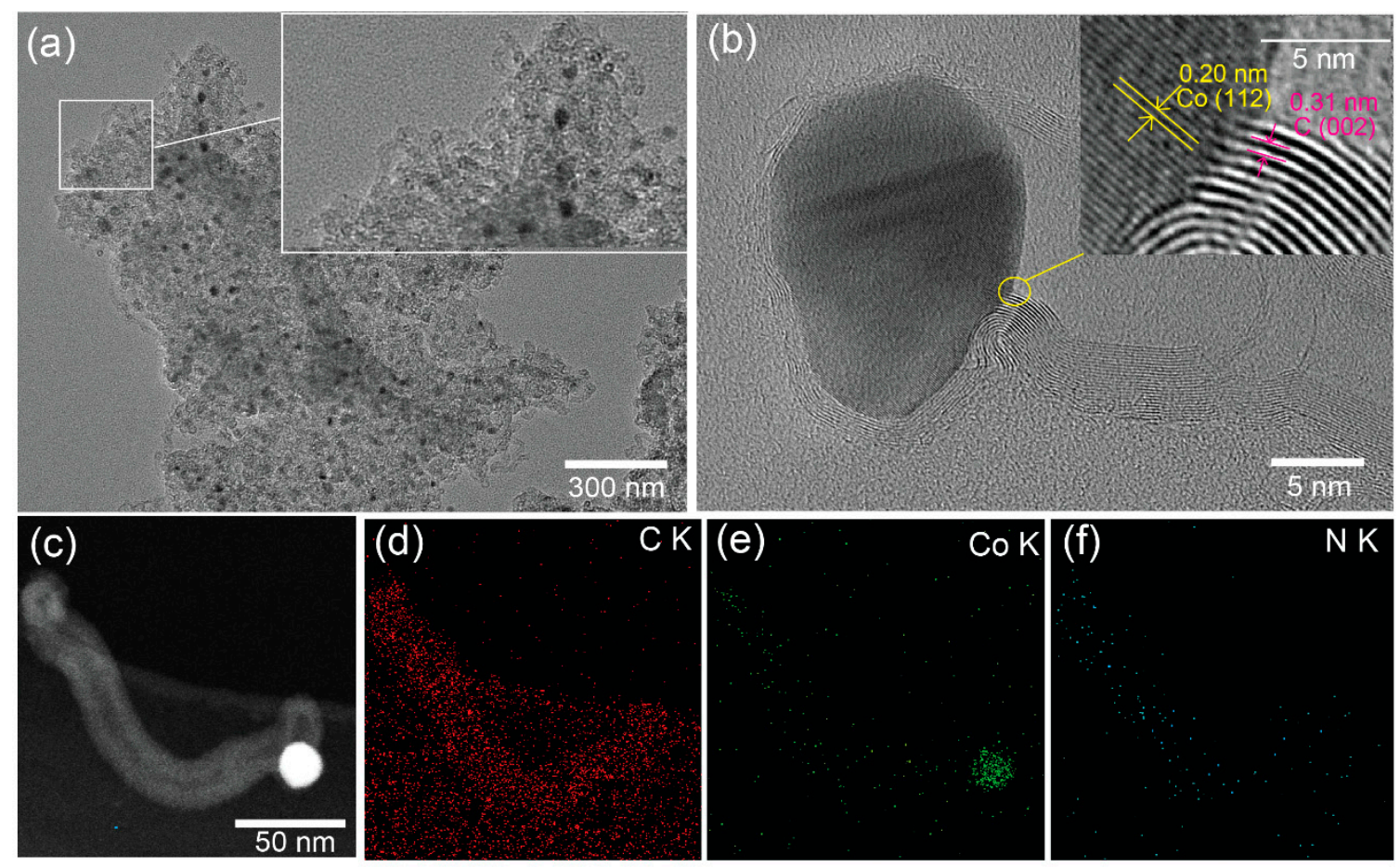

Figure 2. (a) TEM image of Co@CNTs-800; (b) High resolution TEM image of Co@CNTs-800; (c-f) Elemental mapping images of Co@CNTs-800.

X-ray Diffraction (XRD) was performed to show the chemical phase composition and XRD patterns of Co@CNTs-600, Co@CNTs-700, Co@CNTs-800, and Co@CNTs-900, displayed in Figure 3a. The broad peak located at $\sim 26.1^{\circ}$ corresponds to the $C(002)$ plane. The intense peaks of Co@CNTs-600 appearing at $31.8^{\circ}, 34.4^{\circ}$ and $36.3^{\circ}$ were successively assigned to the (100), (002), and (101) planes of $\mathrm{ZnO}$, consistent with the previously reported hexagonal $\mathrm{ZnO}$ (JCPDS no 36-1451). The diffraction peaks appearing at $44.2^{\circ}, 51.5^{\circ}$, and $75.8^{\circ}$ were assigned to the (111), (200) and (220) (planes of cubic Co (JCPDS no 15-0806) [36]. These intense and sharp peaks are indicative of high crystallinity. No other diffraction peaks were seen in the XRD patterns, which demonstrated that no other phases had appeared. The characteristic diffraction peaks of ZnO disappeared in Co@CNTs-700, Co@CNTs-800, and Co@CNTs-900. The ICP-MS analysis revealed that Co@CNTs-800 contained $97.88 \mathrm{wt} \% \mathrm{Co}$ and $2.12 \mathrm{wt} \% \mathrm{Zn}$, respectively. The $\mathrm{Zn}$ species in Co-Zn-BDC volatilized with the higher annealing temperature on account of the low boiling point of Zn during the carbonization [37].

Raman spectra of Co@CNTs-T and Co@C-800 were collected to evaluate the catalyst. As shown in Figure $3 \mathrm{~b}$ and Figure S3a, the peaks appearing at 1350 and $1584 \mathrm{~cm}^{-1}$ were attributed to disordered (D band) and graphite (G band) carbon. The $\mathrm{I}(\mathrm{D}) / \mathrm{I}(\mathrm{G})$ ratio of Co@CNTs-800 was 1.02, which was higher than Co@CNTs-600(1.00), Co@CNTs-700(0.99), Co@CNTs-900(0.74), and Co@C-800(0.91). More defects formed in Co@CNTs-800 which were expected to facilitate the electrocatalytic performance [38]. The Organic Element Analyzer (EA) test was used to analyze the content of C, H, and N. As shown in Table S1, the results showed that the N contents of Co@CNTs-600, Co@CNTs-700, Co@CNTs-800, and Co@CNTs-900 were $2.75 \%, 3.01 \%, 1.87 \%$, and $1.25 \%$. Combined with the Raman results, we concluded that both $\mathrm{N}$ content and defects play an important role in enhancing ORR performance [39]. 

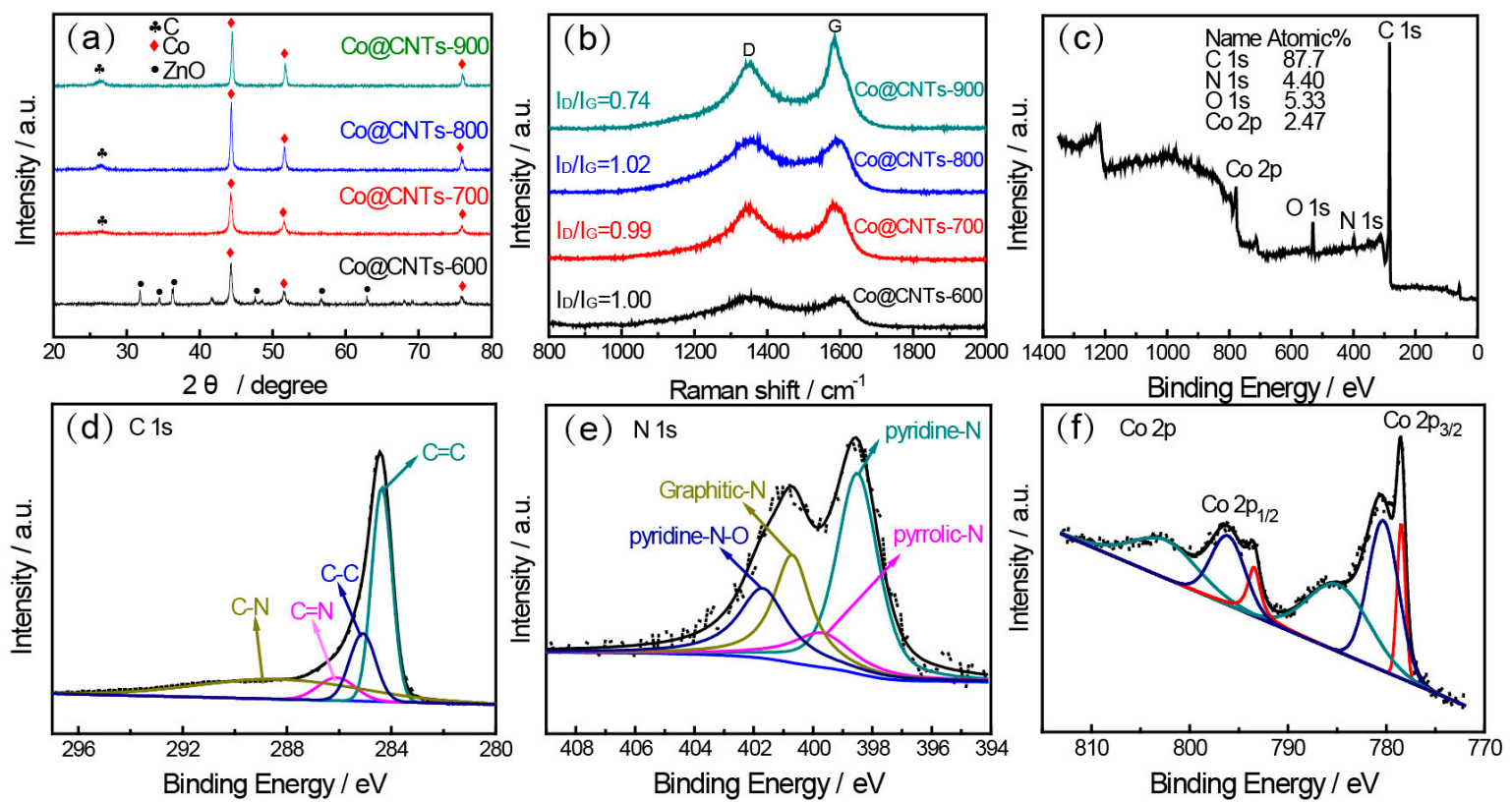

Figure 3. (a) XRD patterns of Co@CNTs-T ( $\mathrm{T}=600,700,800$, and 900, respectively); (b) Raman spectra of Co@CNTs-T ( $\mathrm{T}=600,700,800$, and 900, respectively); (c) XPS survey spectra of Co@CNTs-800; (d) C 1s XPS spectra of Co@CNTs-800; (e) N 1s XPS spectra of Co@CNTs-800; (f) Co 2p XPS spectra of Co@CNTs-800.

X-ray photoelectron spectroscopy (XPS) measurements were then used to investigate chemical configurations and the valence state of Co@CNTs-800. XPS survey spectra in Figure $3 \mathrm{c}$ indicated $\mathrm{C} 1 \mathrm{~s}, \mathrm{~N} 1 \mathrm{~s}, \mathrm{O} 1 \mathrm{~s}$, and $\mathrm{Co} 2 \mathrm{p}$ peaks with no other signals. The contents of $\mathrm{C}, \mathrm{O}, \mathrm{N}$, and Co were $87.7,5.33,4.40$, and $2.47 \mathrm{wt} \%$, respectively. The $\mathrm{C} 1 \mathrm{~s}$ XPS spectrum in Figure $3 \mathrm{~d}$ confirmed four kinds of $\mathrm{C}$ species: $\mathrm{C}=\mathrm{C}(284.4 \mathrm{eV}), \mathrm{C}-\mathrm{C}(285.2 \mathrm{eV}), \mathrm{C}=\mathrm{N}(286.1 \mathrm{eV})$, and C-N $(288.5 \mathrm{eV})[40,41]$. The $\mathrm{N} 1 \mathrm{~s}$ spectra in Figure $3 \mathrm{e}$ can be fitted deconvoluted as four bands at 398.5, 399.7, 400.7, and $401.7 \mathrm{eV}$, which could be attributable to four types of $\mathrm{N}$ species: pyridine- $\mathrm{N}$, pyrrolic-N, graphitic- $\mathrm{N}$, and pyridine- $\mathrm{N}-\mathrm{O}$ [42]. Their proportions were $1.84,0.58,1.06$, and $0.93 \%$, respectively (Figure S3b). Previous studies indicated that pyridine-N and graphitic-N contributed to boosting electrocatalytic activity in ORR [43-45]. We concluded that Co@CNTs-800 had potential as an effective ORR catalyst due to the high proportion of pyridine-N and graphitic-N. The high-resolution Co $2 p$ spectrum is shown in Figure 3f. The binding energies of 778.5 and $793.4 \mathrm{eV}$ were due to $2 \mathrm{p}_{3 / 2}$ and $2 \mathrm{p}_{1 / 2}$ of $\mathrm{Co}^{3+}$. The binding energies of 780.3 and $796.1 \mathrm{eV}$ were assigned to $2 \mathrm{p}_{3 / 2}$ and $2 \mathrm{p}_{1 / 2}$ of $\mathrm{Co}^{2+}$, and peaks located at 784.8 and $802.5 \mathrm{eV}$ were characteristic satellite peaks, consistent with previous reports $[46,47]$. The different valence states of the cobalt active species on the metal nanoparticles were also beneficial in enhancing the electrocatalytic activity [48].

The $\mathrm{N}_{2}$ adsorption/desorption test was used to explore the surface area and pore structures of Co@CNTs-800. As shown in Figure 4a, the Brunner-Emmet-Teller specific surface area was revealed to be $52.7 \mathrm{~m}^{2} \mathrm{~g}^{-1}$. The $\mathrm{N}_{2}$ adsorption/desorption curve exhibited a characteristic type IV isotherm and a distinct hysteresis loop at relative high pressure, demonstrating their mesoporous structure. The pore size distribution curve in Figure $4 \mathrm{~b}$ was used to confirm the mesoporous feature. The pore diameters located at 4.0, 7.6, 10.7, and $28.9 \mathrm{~nm}$ indicated the presence of mesopore, beneficial to the rapid mass transfer process. 

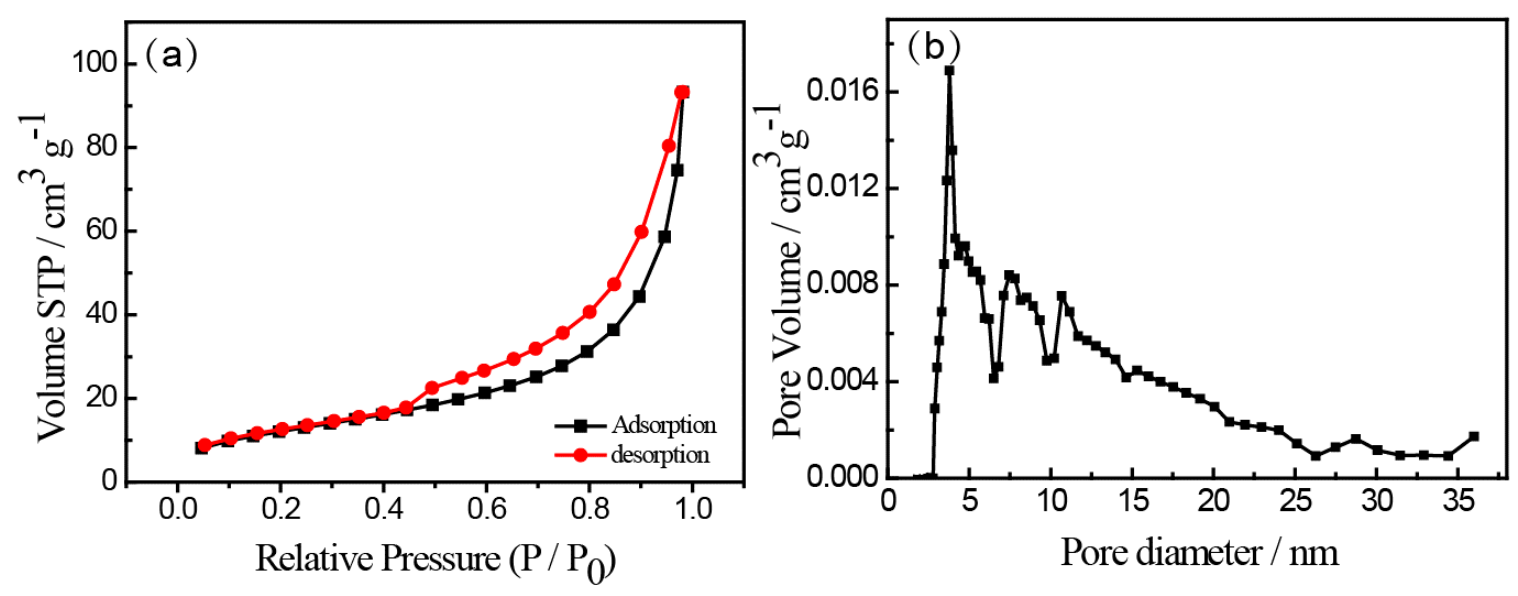

Figure 4. (a) $\mathrm{N}_{2}$ adsorption/desorption isotherms of Co@CNTs-800; (b) Pore size distribution curves of Co@CNTs800.

\subsection{Electrocatalytic Performance}

The electrocatalytic activities of Co@CNTs-600, Co@CNTs-700, Co@CNTs-800 and Co@CNTs-900 were studied by cyclic voltammetry (CV) in $0.1 \mathrm{M} \mathrm{KOH}$ with saturated $\mathrm{O}_{2}$ or saturated $\mathrm{N}_{2}$ at $50 \mathrm{mV} \cdot \mathrm{s}^{-1}$. Figure S4a displays $\mathrm{CV}$ curves of all the electrode materials. No distinct redox peaks in $\mathrm{N}_{2}$ saturated electrolyte can be observed for all the electrode materials, while obvious cathodic peaks appear when in $\mathrm{O}_{2}$-saturated electrolyte. The cathodic peak for Co@CNTs-800 (0.785 V vs. RHE, all potentials refer to RHE herein), was more positive than those of Co@CNTs-600, Co@CNTs-700, and Co@CNTs-900 $(0.677,0.734$, and $0.725 \mathrm{~V}$ respectively). The CV results demonstrated that Co@CNTs- 800 showed better catalytic activity.

The electrocatalytic ORR behavior of Co@CNTs-600, Co@CNTs-700, Co@CNTs-800, and Co@CNTs-900 were further investigated by linear sweep voltammetry (LSV) measurements. Figure 5 a shows the LSV curves of all the electrode materials. The half wave potentials were $0.772,0.817$, and 0.796 V for Co@CNTs-600, Co@CNTs-700, and Co@CNTs900, respectively. For Co@CNTs-800, the half wave potential was the most positive $(0.846 \mathrm{~V})$, which was equivalent to that of the commercial $\mathrm{Pt} / \mathrm{C}$ electrode $(0.846 \mathrm{~V})$. The limiting current was similar $\left(\sim 5.0 \mathrm{~mA} \mathrm{~cm}^{-2}\right)$. The results confirmed that Co@CNTs-800 exhibited better ORR performance than Co@CNTs-600, Co@CNTs-700, and Co@CNTs-900. The ORR performance of Co@CNTs-800 is equal to previously reported non-precious ORR electrocatalysts (Table S2). As shown in Figure S4b, the half wave potentials were 0.767, 0.806, and 0.808 V vs. RHE for blank CNTs, Co-MOF-800, and Co-Zn-MOF-800, respectively, which were lower than that of Co@CNTs-800 (0.846 V vs. RHE). The results indicated that metal centers and the introduction of $\mathrm{N}$ played an important role in facilitating ORR. The electron transfer number and peroxide yield of the Co@CNTs-800 catalyst were calculated by the RRDE technique. In Figure 5b, the electron transfer number of Co@CNTs-800 was calculated as 3.94 and the $\mathrm{H}_{2} \mathrm{O}_{2}$ yield was only $2.63 \%$, which indicated that the 4-electron transfer pathway played a leading role in ORR. The electrochemical stability testing of the Co@CNTs-800 catalyst was investigated by chronoamperometry methods at a potential of 0.7 V. As shown in Figure S4c, the current of Co@CNTs- 800 was more than $90 \%$ retention after a $12 \mathrm{~h}$ test. LSV curves (Figure S4d) were also measured after the $12 \mathrm{~h}$ i-t test. Half wave potential remained almost unchanged, demonstrating the excellent stability of Co@CNTs- 800 as ORR catalyst in alkaline solution. We attributed the excellent stability to the carbon shell surrounding the crystalline Co nanoparticles acting as a protector [34]. 

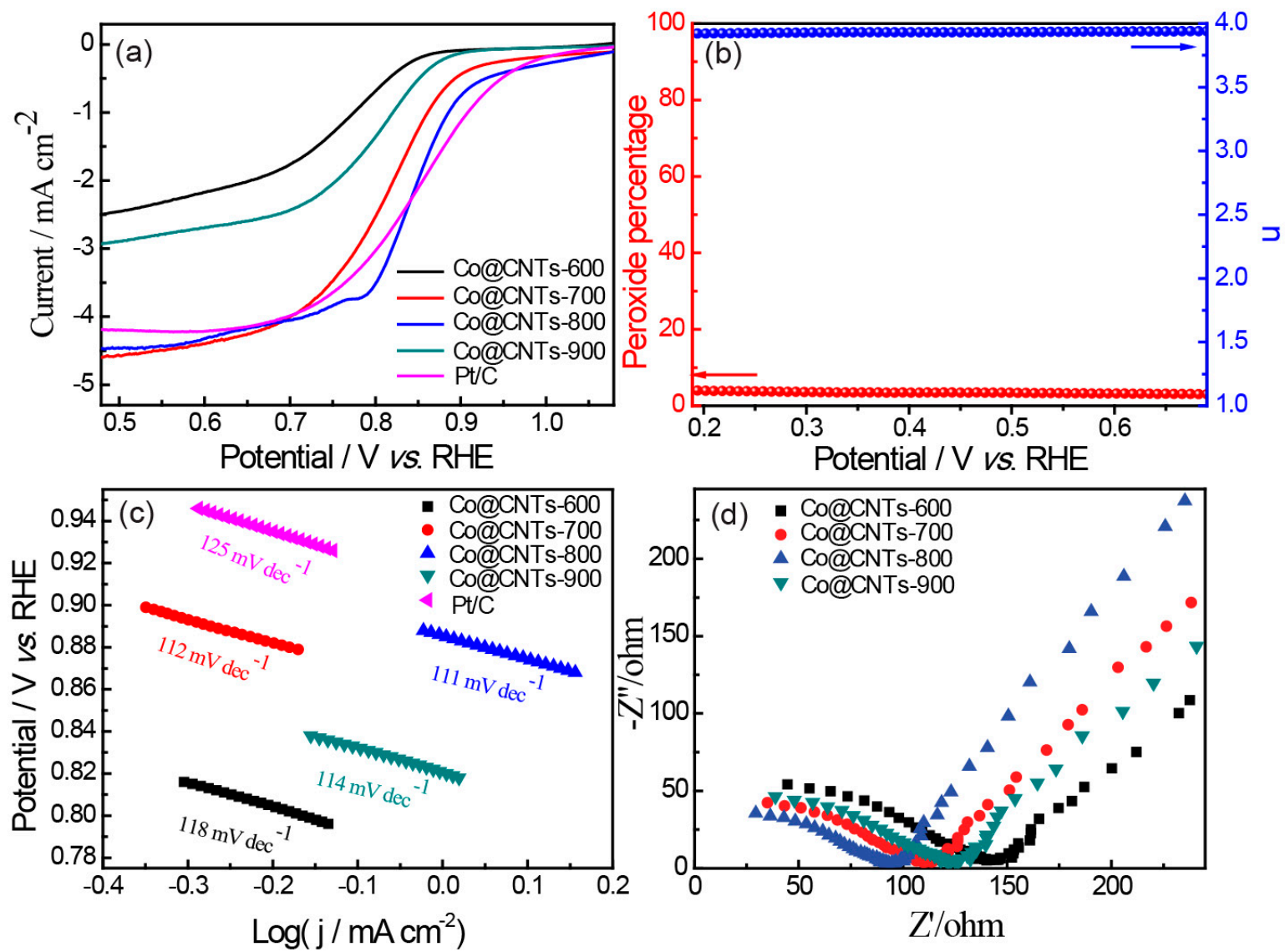

Figure 5. (a) LSV curve of Co@CNTs-T $(\mathrm{T}=600,700,800$ and 900, respectively) and a commercial Pt/C catalyst (1600 rpm); (b) Electron transfer number and peroxide percentage of Co@CNTs-800; (c) Tafel plots of Co@CNTs-T (T=600, 700, 800, and 900, respectively) and a commercial Pt/C; (d) Nyquist plots of Co@CNTs-T (T=600, 700, 800, and 900, respectively).

The Tafel slope values were calculated to further demonstrate the reaction dynamics of the electrocatalysts as shown in Figure 5c, Tafel slope values of Co@CNTs-600, Co@CNTs700, Co@CNTs-800,Co@CNTs-900, and Pt/C were calculated to be 118, 112, 111, 114, and $125 \mathrm{mV} \cdot \mathrm{dec}^{-1}$ respectively, which indicated that Co@CNTs-800 showed the fastest kinetics for electrocatalytic ORR [49]. In addition, electrochemical impedance spectroscopy was recorded in $0.1 \mathrm{M} \mathrm{KOH}$ to determine their ORR behavior. Figure 5d shows the Nyquist plots of all the electrodes. The high frequency semicircles reflect the ion adsorption kinetics and charge transfer resistance (Rct). Co@CNTs-800 with a smaller semicircle showed faster ion adsorption kinetics and charge transfer than Co@CNTs-600, Co@CNTs-700, and Co@CNTs-900. The Warburg length for Co@CNTs- 800 in the $45^{\circ}$ slope lines region in the middle frequency indicated its faster ion diffusion and transport compared to Co@CNTs600, Co@CNTs-700, and Co@CNTs-900 [50]. We concluded that the three-dimensional networks of Co@CNTs-800, formed out of N-doped nanotubes, were beneficial to charge transfer as well as ion diffusion and transport. Thus, Co@CNTs-800 exhibited superior electrochemical activity for ORR.

\section{Conclusions}

In summary, Co@CNTs-800 with a three-dimensional network structure was synthesized by pyrolysis of a mixture of Co-Zn MOF and DCD. A three-dimensional network was formed out of $\mathrm{N}$-doped carbon nanotubes with Co nanoparticles embedded. Benefiting from the nano-tubular structure, the as-prepared Co@CNTs-800 catalyst exhibited fast charge transfer and ion diffusion. In addition, the carbon shell coated on the Co nanoparticles was conducive in enhancing the stability of ORR electrocatalysts. Besides, 
more defects were created by $\mathrm{Zn}$ volatilization and introduction of $\mathrm{N}$ by DCD. Thus, Co@CNTs-800 demonstrated superior electrochemical activity for ORR as well as long-term durability. This work provides a synthetic method to prepare efficient electrocatalysts with three-dimensional networks for ORR.

Supplementary Materials: The following are available online at https:/ /www.mdpi.com/2079-499 1/11/2/261/s1, Figure S1: (a) SEM image of CoZn-BDC; (b) XRD pattern of Co-Zn-BDC; (c) FTIR spectra of Co-Zn-BDC (red) and $\mathrm{H}_{2}$ BDC (black); (d) Thermogravimetric analysis of Co-Zn-BDC. Figure S2: (a) SEM image of Co@CNTs-800 (Co-Zn-BDC:DCD = 1:2); (b) SEM image of Co@CNTs-800 (Co-Zn-BDC:DCD = 2:1). Figure S3: (a) Raman spectra of Co-MOF-800; (b) contents of various N species in Co@CNTs-800. Figure S4: (a) CV curves of Co@CNTs-T catalyst at 600, 700, 800, and $900{ }^{\circ} \mathrm{C}$ in $\mathrm{N}_{2}$ and $\mathrm{O}_{2}$-saturated $0.1 \mathrm{M} \mathrm{KOH}$ solution, respectively; (b) LSV curves of blank CNTs, Co-MOF800, Co-Zn-MOF-800, and Co@CNTs-800; (c) Chronoamperometric responses for Co@CNTs-800 in $\mathrm{O}_{2}$-saturated electrolyte solution at $-0.30 \mathrm{~V}$ (vs. Ag/AgCl); (d) LSV curves of Co@CNTs-800 of initial and after 12 h test. Table S1: The content of N, C, and H for Co@CNTs-600,Co@CNTs-700, Co@CNTs800, and Co@CNTs-900 were determined by an Organic Element Analyzer. Table S2: Comparison of ORR activity of Co@CNTs-800 with the previously reported non-precious ORR electrocatalysts.

Author Contributions: Writing-original draft, Conceptualization, W.Z.; Data curation, X.L. (Xiaoming Liu); Visualization, M.G.; Data curation, H.S.; Supervision, X.L. (Xuanhe Liu). All authors have read and agreed to the published version of the manuscript.

Funding: This research was funded by the National Natural Science Foundation of China, grant number 21603194 and 22001240. This work was also supported by Fundamental Research Funds for the Central Universities (No. 2652018056).

Data Availability Statement: Data is available on the request from the corresponding author.

Conflicts of Interest: The authors declare no conflict of interest. The funders had no role in the design of the study; in the collection, analyses, or interpretation of data; in the writing of the manuscript, or in the decision to publish the results.

\section{References}

1. Li, J.; Zhang, J.; Ye, D.; Zhu, X.; Liao, Q.; Zheng, J. Optimization of inner diameter of tubular bamboo charcoal anode for a microbial fuel cell. Int. J. Hydrog. Energ. 2014, 39, 19242-19248. [CrossRef]

2. Liang, X.; Wang, P.; Li, M.; Zhang, Q.; Wang, Z.; Dai, Y.; Zhang, X.; Liu, Y.; Wang, M.H.; Huang, B. Adsorption of gaseous ethylene via induced polarization on plasmonic photocatalyst $\mathrm{Ag} / \mathrm{AgCl} / \mathrm{TiO}_{2}$ and subsequent photodegradation. Appl. Catal. B-Environ. 2018, 220, 356-361. [CrossRef]

3. Liu, J.; Zhu, D.; Zheng, Y.; Vasileff, A.; Qiao, S.Z. Self-supported earth-abundant nanoarrays as efficient and robust electrocatalysts for energy-related reactions. ACS Catal. 2018, 8, 6707-6732. [CrossRef]

4. Yang, D.; Zhang, L.; Yan, X.; Yao, X. Recent progress in oxygen electrocatalysts for zinc-air batteries. Small. 2017, 1, 17002091700225. [CrossRef]

5. Guo, Y.; Chen, Y.N.; Cui, H.; Zhou, Z. Bifunctional electrocatalysts for rechargeable Zn-air batteries. Chin. J. Catal. 2019, 40, 1298-1310. [CrossRef]

6. LV, H.; Mu, S. Nano-ceramic support materials for low temperature fuel cell catalysts. Nanoscale 2014, 6, 5063-5074. [CrossRef]

7. Liu, J.; Jiao, M.; Lu, L.; Barkholtz, H.M.; Li, Y.; Wang, Y.; Jiang, L.; Wu, Z.; Liu, D.J.; Zhuang, L.; et al. High performance platinum single atom electrocatalyst for oxygen reduction reaction. Nat. Commun. 2017, 8, 15938. [CrossRef]

8. Dai, L.; Xue, Y.; Qu, L.; Choi, H.-J.; Baek, J.-B. Metal-Free Catalysts for Oxygen Reduction Reaction. Chem. Rev. 2015, 115, 4823-4892. [CrossRef]

9. Liu, X.; Dai, L. Carbon-based metal-free catalysts. Nat. Rev Mater. 2016, 1, 16064. [CrossRef]

10. Xu, M.J.; Liu, J.; Ge, J.J.; Liu, C.P.; Xing, W. Research Progress of Metal-Nitrogen-Carbon Catalysts toward Oxygen Reduction Reaction in Changchun Institute of Applied Chemistry. J. Electrochem. 2020, 26, 464-473.

11. Zhang, B.; Zhang, J.; Tan, X.; Tan, D.; Shi, J.; Zhang, F.; Liu, L.; Su, Z.; Han, B.; Zheng, L.; et al. One-step synthesis of ultrathin $\alpha-\mathrm{Co}(\mathrm{OH})_{2}$ nanomeshes and their high electrocatalytic activity toward the oxygen evolution reaction. Chem. Commun. 2018, 54, 4045-4048. [CrossRef] [PubMed]

12. Zhu, Y.; Murali, S.; Stoller, M.D.; Ganesh, K.J.; Cai, W.; Ferreira, P.J.; Pirkle, A.; Wallace, R.M.; Cychosz, K.A.; Thommes, M.; et al. Carbon-based supercapacitors produced by activation of graphene. Science 2011, 332, 1537-1541. [CrossRef] [PubMed]

13. Zhou, X.; Qiao, J.; Yang, L.; Zhang, J. A review of graphene-based nanostructural materials for both catalyst supports and metal-free catalysts in PEM fuel cell oxygen reduction reactions. Adv. Energy Mater. 2014, 4, 1301523. [CrossRef] 
14. Greeley, J.; Stephens, I.E.L.; Bondarenko, A.S.; Johansson, T.P.; Hansen, H.A.; Jaramillo, T.F.; Rossmeisl, J.; Chorkendorff, I.; Nørskov., J.K. Alloys of platinum and early transition metals as oxygen reduction electrocatalysts. Nat. Chem. 2009, 1, 552-556. [CrossRef] [PubMed]

15. Zheng, Y.; Jiao, Y.; Zhu, Y.; Cai, Q.; Vasileff, A.; Li, L.; Han, Y.; Chen, Y.; Qiao, S. Molecule-level g-C3N4 coordinated transition metals as a new class of electrocatalysts for oxygen electrode reactions. J. Am. Chem. Soc. 2017, 139, 3336-3339. [CrossRef] [PubMed]

16. Cheng, Q.Q.; Yang, L.J.; Zou, L.L.; Zou, Z.Q.; Chen, C.; Hu, Z.; Yang, H. Single Cobalt Atom and N Codoped Carbon Nanofibers as Highly Durable Electrocatalyst for Oxygen Reduction Reaction. ACS Catal. 2017, 7, 6864-6871. [CrossRef]

17. He, Y.; Hwang, S.; Cullen, D.A.; Uddin, M.A.; Langhorst, L.; Li, B.; Karakalos, S.; Kropf, A.J.; Wegener, E.C.; Sokolowski, J.M.; et al. Highly active atomically dispersed $\mathrm{CoN}_{4}$ fuel cell cathode catalysts derived from surfactant-assisted MOFs: Carbon-shell confinement strategy. Energy Environ. Sci. 2019, 12, 250-260. [CrossRef]

18. Gao, K.; Wang, B.; Tao, L.; Cunning, B.V.; Zhang, Z.; Wang, S.; Ruoff, R.; Qu, L. Efficient Metal-Free Electrocatalysts from N-Doped Carbon Nanomaterials: Mono-Doping and Co-Doping. Adv. Mater. 2019, 31, 1805121. [CrossRef]

19. Qu, K.; Zheng, Y.; Dai, S.; Qiao, S. Graphene oxide-polydopamine derived N, S-codoped carbon nanosheets as superior bifunctional electrocatalysts for oxygen reduction and evolution. Nano Energy 2016, 19, 373-381. [CrossRef]

20. Yan, D.; Li, Y.; Huo, J.; Chen, R.; Dai, L.; Wang, S. Defect chemistry of nonprecious-metal electrocatalysts for oxygen reactions. Adv. Mater. 2017, 29, 1606459. [CrossRef]

21. Zhang, R.; Zhang, Y.C.; Pan, L.; Shen, G.-Q.; Mahmood, N.; Ma, Y.-H.; Shi, Y.; Jia, W.; Wang, L.; Zhang, X.; et al. Engineering cobalt defects in cobalt oxide for highly efficient electrocatalytic oxygen evolution. ACS Catal. 2018, 8, 3803-3811. [CrossRef]

22. Hu, C.; Yi, Z.; She, W.; Wang, J.; Xiao, J.; Wang, S. Urchin-like non-precious-metal bifunctional oxygen electrocatalysts: Boosting the catalytic activity via the In-situ growth of heteroatom (N, S)-doped carbon nanotube on mesoporous cobalt sulfide/carbon spheres. J. Colloid Interf. Sci. 2018, 524, 465-474. [CrossRef] [PubMed]

23. Zhou, H.C.; Long, J.R.; Yaghi, O.M. Introduction to metal-organic frameworks. Chem. Rev. 2012, 112, 673-674. [CrossRef] [PubMed]

24. Feldblyum, J.I.; Wong-Foy, A.G.; Matzger, A.J. Non-interpenetrated IRMOF-8: Synthesis, activation, and gas sorption. Chem. Commun. 2012, 79, 9828-9830. [CrossRef] [PubMed]

25. Dau, P.V.; Tanabea, K.K.; Cohen, S.M. Functional group effects on metal-organic framework topology. Chem. Commun. 2012, 48, 9370-9372. [CrossRef] [PubMed]

26. Kalidindi, S.B.; Wiktor, C.; Ramakrishnan, A.; Weßing, J.; Schneemann, R.; Tendeloob, G.V.; Fischer, R.A. Lewis base mediated efficient synthesis and solvation-like host-guest chemistry of covalent organic framework-1. Chem. Commun. 2013, 49, 463-465. [CrossRef]

27. Li, Y.; Jia, B.; Fan, Y.; Zhu, K.; Li, G.; Su, C.-Y. Bimetallic zeolitic imidazolite framework derived carbon nanotubes embedded with Co nanoparticles for efficient bifunctional oxygen electrocatalyst. Adv. Energy Mater. 2018, 8, 1702048. [CrossRef]

28. Peera, S.G.; Balamurugan, J.; Kim, N.H.; Lee, J.H. Sustainable Synthesis of Co@NC Core Shell Nanostructures from Metal Organic Frameworks via Mechanochemical Coordination Self-Assembly: An Efficient Electrocatalyst for Oxygen Reduction Reaction. Small 2018, 14, 1800441. [CrossRef]

29. Wang, H.F.; Chen, L.; Pang, H.; Kaskel, S.; Xu, Q. MOF-derived electrocatalysts for oxygen reduction, oxygen evolution and hydrogen evolution reactions. Chem. Soc. Rev. 2020, 49, 1414-1448. [CrossRef]

30. Zhao, S.; Wang, Y.; Dong, J.; He, C.-T.; Yin, H.; An, P.; Zhao, K.; Zhang, X.; Gao, C.; Zhang, L.; et al. Ultrathin metal-organic framework nanosheets for electrocatalytic oxygen evolution. Nat. Energy 2016, 1, 1-10. [CrossRef]

31. Han, B.; Ou, X.; Deng, Z.; Han, B.; Ou, X.; Deng, Z.; Song, Y.; Tian, C.; Deng, H.; Xu, Y.-J.; et al. Ni Metal-Organic Frameworks Monolayers for Photoreduction of Diluted $\mathrm{CO}_{2}$ : Metal Nodes-Dependent Activity and Selectivity. Angew. Chem. In. Ed. 2018, 57, 16811-16815. [CrossRef] [PubMed]

32. Furukawa, H.; Cordova, K.E.; O'Keeffe, M.; Yaghi, O.M. The chemistry and applications of metal-organic frameworks. Science 2013, 341, 6149. [CrossRef] [PubMed]

33. Liu, X.; Min, S.; Xue, Y.; Tian, L.; Lei, Y.; Wang, F. In situ growth and activation of an amorphous MoS x catalyst on Co-containing metal-organic framework nanosheets for highly efficient dye-sensitized $\mathrm{H}_{2}$ evolution. New J. Chem. 2019, 43, 4152-4159. [CrossRef]

34. Deng, J.; Ren, P.; Deng, D.; Yu, L.; Yang, F.; Bao, X. Highly active and durable non-precious-metal catalysts encapsulated in carbon nanotubes for hydrogen evolution reaction. Energy Environ. Sci. 2014, 7, 1919-1923. [CrossRef]

35. Feng, T.; Qin, H.; Zhang, M. Co@C Nanoparticle Embedded Hierarchically Porous N-Doped Hollow Carbon for Efficient Oxygen Reduction. Chem. Eur. J. 2018, 24, 10178-10185. [CrossRef] [PubMed]

36. Li, Y.; Cheng, F.; Zhang, J.; Chen, Z.; Xu, Q.; Guo, S. Cobalt-Carbon Core-Shell Nanoparticles Aligned on Wrinkle of N-Doped Carbon Nanosheets with Pt-Like Activity for Oxygen Reduction. Small 2016, 12, 2839-2845. [CrossRef]

37. Meng, Z.; Cai, S.; Wang, R.; Tang, H.; Song, S.; Tsiakarascde, P. Bimetallic-Organic Framework-derived Hierarchically Porous Co-Zn-N-C as Efficient Catalyst for Acidic Oxygen Reduction Reaction. Appl. Catal. B-Environ. 2019, 244, 120-127. [CrossRef]

38. Palaniselvam, T.; Kashyap, V.; Bhange, S.N.; Baek, J.B.; Kurungot, S. Nanoporous graphene enriched with Fe/Co-N active sites as a promising oxygen reduction electrocatalyst for anion exchange membrane fuel cells. Adv. Funct. Mater. 2016, 26, $2150-2162$. [CrossRef] 
39. Yu, H.; Shang, L.; Bian, T.; Shi, R.; Waterhouse, G.I.N.; Zhao, Y.; Zhou, C.; Wu, L.-Z.; Tung, C.-H.; Zhang, T. Nitrogen-Doped Porous Carbon Nanosheets Templated from g-C3N4 as Metal-Free Electrocatalysts for Efficient Oxygen Reduction Reaction. Adv. Mater. 2016, 28, 5080-5086. [CrossRef]

40. Zhang, L.; Su, Z.; Jiang, F.; Yang, L.; Qian, J.; Zhou, Y.; Li, W.; Hong, M. Highly graphitized nitrogen-doped porous carbon nanopolyhedra derived from ZIF-8 nanocrystals as efficient electrocatalysts for oxygen reduction reactions. Nanoscale 2014, 6, 6590-6602. [CrossRef]

41. Dong, T.; Zhang, X.; Cao, Y.; Chen, H.-S.; Yang, P. Ni/Ni $\mathrm{Ni}_{3} \mathrm{C}$ core-shell nanoparticles encapsulated in N-doped bamboo-like carbon nanotubes towards efficient overall water splitting. Inorg. Chem. Front. 2019, 6, 1073-1080. [CrossRef]

42. Yang, D.; Velamakanni, A.; Bozoklu, G.; Park, S.; Stoller, M.; Piner, R.D.; Stankovich, S.; Jung, I.; Field, D.A.; Ventrice, C.A.; et al. Chemical analysis of graphene oxide films after heat and chemical treatments by X-ray photoelectron and Micro-Raman spectroscopy. Carbon 2009, 47, 145-152. [CrossRef]

43. Jena, H.S.; Krishnaraj, C.; Parwaiz, S.; Lecoeuvre, F.; Schmidt, J.; Pradhan, D.; Van Der Voort, P. Illustrating the Role of Quaternary$\mathrm{N}$ of BINOL Covalent Triazine-Based Frameworks in Oxygen Reduction and Hydrogen Evolution Reactions. ACS Appl. Mater Inter. 2020, 12, 44689-44699. [CrossRef] [PubMed]

44. Zhang, J.; Wang, X.; Qin, D.; Xue, Z.; Lu, X. Fabrication of iron-doped cobalt oxide nanocomposite films by electrodeposition and application as electrocatalyst for oxygen reduction reaction. Appl. Surf. Sci. 2014, 320, 73-82. [CrossRef]

45. Fei, H.; Dong, J.; Arellano-Jiménez, M.J.; Ye, G.; Kim, N.; Samuel, E.; Peng, Z.; Zhu, Z.; Qin, F.; Bao, J.; et al. Atomic cobalt on nitrogen-doped graphene for hydrogen generation. Nat. Commun. 2015, 6, 1-8. [CrossRef] [PubMed]

46. Zhang, T.; Wu, J.; Xu, Y.; Wang, X.; Ni, J.; Li, Y.; Niemantsverdriet, H. Cobalt and cobalt carbide on alumina/NiAl (110) as a catalyst model. Catal. Sci Technol. 2017, 7, 5893-5899. [CrossRef]

47. Han, H.; Bai, Z.; Wang, X.; Chao, S.; Liu, J.; Kong, Q.; Yang, X.; Yang, L. Highly Dispersed Co Nanoparticles Inlayed in S, N-doped Hierarchical Carbon Nanoprisms Derived from Co-MOFs as Efficient Electrocatalysts for Oxygen Reduction Reaction. Catal. Today 2018, 318, 126-131. [CrossRef]

48. Lu, H.S.; Zhang, H.; Liu, R.; Zhang, X.; Zhao, H.; Wang, G. Macroscale cobalt-MOFs derived metallic Co nanoparticles embedded in N-doped porous carbon layers as efficient oxygen electrocatalysts. Appl. Surf. Sci. 2017, 392, 402-409. [CrossRef]

49. Liu, X.; Yang, W.; Chen, L.; Liu, Z.; Long, L.; Wang, S.; Liu, C.; Dong, S.; Jia, J. Graphitic Carbon Nitride (g-C $\left.\mathrm{C}_{3} \mathrm{~N}_{4}\right)$-Derived Bamboo-Like Carbon Nanotubes/Co Nanoparticles Hybrids for Highly Efficient Electrocatalytic Oxygen Reduction. ACS Appl. Mater. Inter. 2020, 12, 4463-4472. [CrossRef]

50. Liu, X.; Zhuo, M.; Zhang, W.; Gao, M.; Liu, X.-H.; Sun, B.; Wu, J. One-step ultrasonic synthesis of Co/Ni-catecholates for improved performance in oxygen reduction reaction. Ultrason. Sonochem. 2020, 67, 105179. [CrossRef] 